\title{
Lost in translation? A background to action research into teacher education and training in China through interpreters
}

\author{
Zeng Jiajin \\ Guangdong Polytechnic Normal University, China \\ HUDCETT
}

\author{
Jane Burrows \\ University of Huddersfield
}

\begin{abstract}
This paper provides a background for action research in China. The context is a training programme for Chinese vocational practitioners led by British Teacher Educators, teaching through Chinese interpreters. Teacher education and training in China are outlined, and an author case study provided. Global trends in vocational education have been considered, and reference made to the Chinese government's plans for reforming and developing education. The Vocational Education and Training (VET) programmes have been summarised to set the scene for the action research that will be reported in a further paper, which will consider the ways in which teaching through interpretation affects both learning and teaching on these programmes.
\end{abstract}

In this paper, the following terms apply: the trainer is the United Kingdom (UK) Teacher Educator, the interpreter is the member of the Chinese university staff who interprets on the training programme and the teachers are the Chinese teachers attending the training.

\section{Key words}

Interpretation; Vocational Education; Teacher Education; Teaching; Learning.

\section{Introduction}

The Vocational Education and Training (VET) Project is a contract between a UK university and a Chinese university based in the Guangdong Province. The programme started in 2011. UK Teacher Educators travel to China, usually on a monthly basis, to lead the training. The Chinese institution organises training venues and accommodation, provides interpreters and looks after the visiting lecturers. The two authors have worked together, and with other professionals, on many occasions. One of the authors is a Chinese lecturer of English who works as an interpreter on the VET programmes, the other is a UK teacher trainer; hence, both Chinese and Western perspectives will inform the research. Based on their experiences, it was concluded that working on the VET programme would provide a rich seam of research that could potentially contribute to deeper understanding of the issues inherent in the use of interpretation in learning and teaching $_{2}$ and provide a foundation for further research in this area, both in the UK and in China.

There appears to be a paucity of academic literature on the subject of learning and teaching through an interpreter. Research has uncovered publications about the use of interpreters in social work (Baker, 1981) and medicine (Jacobs et al, 2009; Smith et al, 2006), and references to these works have been provided in the bibliography. There is some information on the issues faced by deaf students who require the services of interpreters in mainstream education; for example, Foster et al (1999). However, very little has yet been discovered about training teachers in a situation where the trainer speaks the minority language (in this case, English) and the attendees speak the source language (Chinese).

\section{Teacher Education and Training in China}


All teachers must gain the Teacher's Qualification Certificate (TQC), introduced in 2000, before starting work. It is described as providing the teachers '... with a series of complete and continuous learning experience and activities, [so] the teachers achieve improvement in their profession, academy and personal character' (Puquan, 2003: p. 128).

Pre-service teacher training courses are four year programmes. Core education studies include psychology, theory and pedagogy; the students also study their own subject specialism. There is a compulsory teaching practice element lasting one semester. Pre-service students must pass the Putonghua Standard Proficiency Test (known simply as the Putonghua Shuiping Ceshi-PSC) at Level 2B or above to gain the TQC. Putonghua is the Chinese official language and PSC is an official proficiency test issued by the Ministry of Education of the People's Republic of China, aiming to examine and accurately assess candidates' mastery of the language. The test is administered at three levels (1,2 and 3), with each level being graded A, B or C in accordance with candidates' scores in the test (moe.gov.cn).

Graduates and recruits from industry must also gain the TQC. This involves:

1. registering for educational courses including pedagogy and psychology in an authorised organisation, usually a normal university, for no less than 32 hours per subject

2. passing the National Teacher's Qualification examination

3. passing the Putonghua Test at Level $2 \mathrm{~B}$ or above

4. taking a standard competency test, which includes planning and teaching a learning session

5. passing an interview, which assesses the applicant's appearance, communication skills and knowledge of educational theory amongst other things.

'Teachers in vocational schools are either recruited directly as graduates or from industry' (OECD, 2010: p. 17). This was the case with one of the authors:

Case Study - Zeng Jiajin: My own example is that of a university, but the same procedure is followed in vocational colleges and schools. In 1999, while working as a marketing manager in an American company, I applied for a position in the College English Department at a local university, passed an interview and was required to give what was called a 'trial teaching presentation'. I was given a textbook, with information on the unit to be taught, but no further guidance on content, so I prepared the whole unit. Though it was called a 'trial', I actually gave a real lesson to a class of real students and the class teacher and other teachers from College English Department all attended. Even though I did not finish everything I had prepared, I was offered the job. I then had to register on a training programme at another university, where I took three courses (32 hours per course) during weekends. They were: Higher Education; Psychology of Higher Education; University Teacher's Professional Ethics. I passed all the subject tests and got a Certificate of Completion for University Teacher's Pre-service Training. In 2000, according to government requirement, I passed Putonghua Test with 2B Level and gained my TQC.

These recruits learn the complex job of teaching by doing and imitating others and will often teach as they themselves were taught, reproducing the 'teacher transmit - student receive' mode that dominated their own learning, a far cry from Light and Cox, who say 'teaching should not be thought of as transmission but as an engagement...' (2001: p. 56). Teacher Educators in the UK will be familiar with this dilemma of trainees' preconceptions 
that learning is about didactic teacher practice, particularly perhaps with in-service trainees.

The Chinese government has emphasised the need for development in teacher training, in line with its reform of the education system, to promote teaching competence and the ethos of Lifelong Learning. 'We will advocate teaching to be heuristic, exploratory, discussion-based, and participatory, and help students learn how to study. We will stimulate students' curiosity, develop their interests and hobbies, and foster a fine environment for independent thinking, exploration and innovation' (Outline of China's National Plan for Medium and Long-term Education Reform and Development [2010-2020] aei.gov.au).

In an attempt to foster practical skills in new, creative teachers, the government has established a training system for all staff to upgrade their professional competence. Different forms of in-service training have been conducted; for example, Song Jiao Shang Men, which involves sending trainers to rural schools and colleges to help teachers develop modern vocational education and teaching strategies. Foreign experts are invited to give lectures in modern pedagogy, to provide different perspectives for Chinese teachers to consider.

There is also compulsory Continuing Professional Development (CPD), regulations for which vary between provinces. In Guangdong province, teachers are required to do at least 72 hours of CPD annually. CPD contains three strands: general, specialised and optional. The decisions about which courses to take are made through negotiation between the individual and their organisation. For specialised and optional courses, professionals can complete training in authorised teaching organisations, in scientific research and production units or by attending academic conferences and seminars, and through distance learning.

Teacher training and education aim to provide guidance for teachers' practice and encourage action research arising from that practice. However, as teaching and training in China tend to be heavily didactic and teacher-centred, this has proved hard to achieve; the Chinese author's experience is that teacher training in China is theory-centred, trainertransmitted with little application or reference to a teacher's specialism, contexts and experiences. The didactic approach has its roots in Confucian dialogical method. Unlike the Socratic method, in which knowledge is advanced through questioning, Confucian philosophy emphasises the acquisition and understanding of concepts followed by discussion and questioning:

'Silence, rather than an indicator of a lack of engagement in the process of learning, regarded pejoratively by many Western academics...is thus an active process...beneficial to higher levels of thinking and to deepening understanding'.

(Trahar, 2007: p. 14)

Teaching in China (as in many other parts of the world) relies heavily on PowerPoint presentations - many Chinese teachers report having to 'turn in' a PowerPoint presentation for each and every lesson they give. However, there is a reason for this classes are so large that, often, it can seem that teacher exposition is the only way to cover the content of a very heavy curriculum. As Biggs remarks, a change in activity '...restores attention and concentration...' (2003: p. 102), but it is a daunting prospect for many Chinese teachers to formulate and manage a variety of activities in their normal 40 to 45 minute lessons with such large numbers of students. 
Some Chinese students will never be in classes of fewer than 60, with some rising to 200 or 250, especially for some general courses. Many Chinese teachers never teach classes of fewer than 60 - how, then, to introduce a more varied approach to learning when faced with large numbers of students in packed classrooms and with very few resources?

It has already been mentioned above that the Chinese government advocates that teaching and learning should be 'exploratory, discussion-based and participatory'. The VET programmes have not been designed to preach 'West is best'; rather, they demonstrate a variety of student-centred teaching and learning strategies, the value of which the teachers decide for themselves in their work to develop in their students appropriate employability skills, for example collaborative working, effective communication and problem solving.

\section{Vocational education and training in China}

In China, students with better grades usually choose elite universities, with vocational education perceived as inferior to purely academic study, as is the case in many parts of the world, for example Croatia, where '...due to the poor esteem of vocational education it has been difficult, over many years, to recruit teachers and trainers into the vocational education system...' (Cindric and Petricevic, 2013: p. 4). The Chinese government is pursuing an energetic development of vocational education. This is in line with international trends and reforms; for example, for the last ten years, there has been enhanced political cooperation in Europe on the development of vocational education and training, culminating in the adoption of the Bruges Communiqué in 2010, which defines '... an ambitious agenda for modernising vocational education and training systems in Europe...' (ec.europa.eu). In 2012, President Obama committed eight billion dollars in America to develop partnerships between colleges and employers to train two million workers in high-growth industries like advanced manufacturing and health care (americanprogress.org).

Between 1980 and 2001, the proportion of Chinese secondary vocational school students increased from 19 per cent to 45.3 per cent, and during the years 1980 to 2011, Chinese vocational Higher Education Institutions produced 50 million graduates who would seek employment as technical workers and managers (China.org.cn). The stated aim of the government is that, by 2020 :

'... a modern vocational education system with well coordinated secondary and higher vocational education shall have come to stay to meet the requirements of adjusting the economic development mode and restructuring the industries, to embody the philosophy for lifelong education, and to satisfy the demand of the people for vocational education and the needs of the economy and society for high-caliber [sic] workers and skilled personnel.'

(Outline of China's National Plan for Medium and Long-term Education Reform and Development [2010-2020] aei.gov.au)

The vocational curriculum is divided into three parts:

'... about one third for general academic skills defined nationally by the Ministry of Education, about one third defined nationally associated with the particular occupation, and finally about one third, also in the occupational field, determined locally according to local needs, sometimes at school level.

(OECD, 2010: p. 14) 
There are 270 vocational specialities nationally, divided into 13 groups, among which are agriculture and forestation, resource and environment, energy, manufacturing, medicine and health. Vocational teachers are required to spend two months every two years in industry to ensure their knowledge and skills are updated and made current (OECD, 2010).

\section{The VET programme}

There are two courses, VET 1 and VET 2, each of them of six days' duration. The participants are teachers who work in vocational schools and colleges. The training cycle comprises three days followed by a break (which can vary between one and seven days), then a further three days. VET 1 is an introduction to student-centred learning, which is 'a system of providing learning which has the student at its heart' (Brandes and Ginnis, 1986: p. 1). During the first three days, the teachers participate in activities that demonstrate the principles of student-centred learning, explore appropriate theory and consider varied learning and assessment methods that they could potentially apply to their own teaching. Following the break in training, the teachers return and, in groups, teach lessons that utilise student-centred strategies in which the other course members are the participants. Feedback on these lessons is provided, both orally and in writing, by the teachers and the trainer.

VET 2 follows the same cycle (three days, rest, three days) and is concerned with curriculum design utilising principles of student-centred learning. After the break in training, the teachers give group presentations, usually in subject groups, demonstrating how they could utilise different curriculum models and student-centred learning strategies to revise their curriculum design, plan and deliver learning; again, feedback from fellow participants and the trainer ensues.

Despite the nomenclature, there does not have to be progression from VET 1 to VET 2. Some training groups will complete VET 2 without having done VET 1 and others will only participate in VET 1 training. A small minority of Chinese teachers will complete both VET 1 and VET 2. The choice about the programme(s) offered is made in China by the schools/colleges in consultation with representatives from the Chinese university.

\section{The context for research}

The VET course materials are prepared in the UK, translated into Chinese and provided both electronically and in hard copy format. Every interpreter is a specialist English teacher drawn from the Chinese university staff. Interpreting on the VET programmes is popular, as it provides a good source of CPD that would be difficult to achieve otherwise. UK staff often present new concepts and ideas that need prior research by the interpreters and careful explanation in the training room. Therefore, the interpreter needs to have detailed knowledge to be able to present the information clearly and succinctly.

Laying down the appropriate foundations of complex relationships is central to the wellbeing of all concerned. 'What is important is...the climate and relationships which are formed (Gould, 2009: p. 81). The most important factor is that of communication; it is vital that the English and Chinese personnel talk to each other, to become familiar with speech patterns, language, vocabulary, accents etc. This familiarity forms the basis of successful interpretation both within, and outside of, the learning environment. Professional relationships have to be formed quickly and effectively between trainer and interpreters, trainer and teachers, and interpreter and teachers. 
The Chinese teachers attending the training can be specialists in any of the 270 subjects in the vocational curriculum. All training groups (varying in size between 30 and 45) have a range of subject specialisms represented, from Chinese medicine to hydraulic engineering. Very often, there will be teachers of English also present, who relish the opportunity the training provides for developing their listening and speaking skills in the presence of a native English speaker.

English is an important subject in the Chinese curriculum and is taught at all levels. Chinese students take important examinations at the age of 14 and it is at this point that their futures are often decided. Ability in English is one of the determining factors that affect their potential studies. Higher scoring students are destined for academic schools and universities, while lower scoring students attend vocational schools and universities. It is important to recognise that all the Chinese teachers on the VET programmes have studied English and may have good receptive skills. However, as with all language learning, productive skills can be less refined.

Everything the trainer says has to be translated for the benefit of all and it is a challenge for the trainers to alter their normal speech patterns and ensure that they speak clearly and succinctly, preferably in concise sentences that can be translated more easily by the interpreter. One trainer noted some of the difficulties encountered:

'On the technical side, mistranslations were only discovered when they had an effect on an outcome. Examples included "free-standing" becoming "threelegged" in an instruction (misheard: "three standing") and a comment by the trainer on how nuclear power stations had been proven to be a danger as a result of the Japanese tsunami leading to stunned silence. The translator explained that she had "told them about the nuclear bomb attack on Hiroshima, in Japan"'

(Denby, 2012: p. 4)

The focus of the VET programmes is on professionals working together to achieve their aims. The interpreter is the bridge between the English member of staff and the Chinese teachers with whom they are working, using their professional training and expertise to facilitate, and assist in organising, the training. Not only must the interpreter understand the content, they must also be able to bridge the gap between English and Chinese in terms of culture, social mores, attitudes and understanding. For example, de Bono's green hat (de Bono, 2009) is problematic as a green hat in China represents a cuckold and numbering can provide difficulties, as four is an unlucky number, while six, eight and nine are considered the opposite. Very often, the interpreter can prevent any faux pas and can guide the English trainer through the maze of communicative, linguistic and social barriers.

However, there is a balance to be struck between breaking down barriers and the introduction of filters and distortion by the interpreter. Launer says of Nigerian interpreters:

'The interpreters often did not provide word-for-word translations of what the doctor or patient had said. Some of these deviations were helpful, but others were confusing or incorrect'.

Despite common usage, translating and interpreting are not interchangeable terms. Translation is the transference of meaning from text to text, with the translator able to access dictionaries and glossaries to produce an accurate translation of one language into another. The interpreter grasps a complex concept in one language, chooses the most 
appropriate vocabulary and conveys the message faithfully in a target language, to ensure linguistic, emotional, tonal and cultural equivalence, all in real time. There can be time lapses in interpreting, as interpreted messages can be shorter or longer than the original messages, depending on the languages used. Interpreting often requires a processing time, in which the interpreter rearranges grammar appropriately and selects accurate vocabulary, before starting the message. When working with interpreters, it is important to remember processing time in order to avoid accidently interrupting one another, and to receive the entire message.

The need for translation necessarily slows the training, which is why establishing a rhythm and understanding with the interpreter is so important. The trainer has to work with multiple interpreters during their time in China and this requires adapting and responding rapidly to any differences in technique. When there is a single Chinese speaker addressing the class as a whole, some of the interpreters do chuchotage for the English trainer - that is, they will whisper a simultaneous translation while the Chinese speaker is talking - which certainly helps sessions progress more swiftly.

The interpreter makes a significant contribution to the learning environment. This includes physical resources, atmosphere, management of expectations (of both the English and Chinese personnel) and timings. Any issues that arise must be dealt with sensitively and with empathy, to prevent escalation. As the reasons for them stem mostly from different cultural perspectives, the interpreter must be able to demonstrate understanding of both English and Chinese points of view and explain these appropriately. The English staff must be receptive to the explanations, must actively seek to understand the Chinese culture in which they are, albeit temporarily, working, and also ensure that the important messages inherent in the training are not compromised.

In short, teaching through interpreters can be a minefield through which navigation can be problematic. The authors have worked together, and with other professionals, on numerous occasions. The action research that will be reported in a second paper concerns the effects that the use of interpretation can have on learning and teaching. The report will comprise analysis of questionnaires, focus group discussion and interviews, to provide some insight into the associated challenges.

\section{References}

Baker, N. G. (1981) 'Social Work Through An Interpreter', Social Work Vol. 26, No. 5, pp. 391-397.

Biggs, J. (2003) Teaching For Quality Learning At University ( $2^{\text {nd }}$ ed.). Maidenhead: Open University Press.

Brandes, D., Ginnis, P. (1986) A Guide To Student-Centred Learning. Cheltenham: Nelson Thornes.

Cindric, M., Petricevic, D. (2013) Teachers' And Trainers' Training In Vocational Education European Training Foundation Research Project www.national-observatory.org [accessed 12 February 2013].

de Bono, E. (2009) Six Thinking Hats: An Essential Approach To Business Management. London: Penguin.

Denby, N. (2012) 'An Investigation Into The Use Of The iPad, When Teaching In China, To Help Overcome Language Barriers And Assist Reflection', Proceedings of $2^{\text {nd }}$ Annual International Conference on Education and e-learning. (Eel 2012) Bali, Indonesia. 
Foster, S., Long, G., Snell, K. (1999) 'Inclusive Instruction And Learning For Deaf Students In Postsecondary Education', Journal of Deaf Studies and Deaf Education Vol. 4, No. 3, pp. 225-235. Oxford Journals http://jdsde.oxfordjournals.org/content/4/3/225.full.pdf+html [accessed 28

December 2012].

Gould, J. (2009) Learning Theory And Classroom Practice In The Lifelong Learning Sector. Exeter: Learning Matters.

Jacobs, E.A., Diamond, L.C., Stevak, L. (2009) 'The Importance Of Teaching Clinicians When And How To Work With Interpreters', Patient Education and Counseling Vol. 78, Issue 2, pp. 149-153.

Launer, J. (1978) 'Taking Medical Histories Through Interpreters: Practice In A Nigerian Outpatient Department', British Medical Journal Vol. 2, pp. 934.

Light, G., Cox, R. (2001) Learning And Teaching In Higher Education: The Reflective Professional. London: Paul Chapman.

OECD (2010) Learning For Jobs, OECD Reviews Of Education And Training, Options For China. Paris: OECD.

Smith, W., Betancourt, J., Wynia, M., Bussey-Jones, J., Stone, V., Phillips, C., Fernandez, A., Jacobs, E., Bowles, J. (2006) 'Recommendations For Teaching About Racial And Ethnic Disparities In Health And Health Care', Society of General Internal Medicine Health Disparities Task Force http://www.medschool.vcu.edu/gme/ed_resources/documents/EducationalStrategiesinHealthDispa ritiesPaper05Nov27.pdf [accessed 28 December 2012].

黄甫全(2003) 新课程中的教师角色与教师培训【M】北京: 人民教育出版社, 2003:128. [Trans: Huang, P. (2003) Teacher's Role And Teacher's Training With The New Curriculum. Beijing: People's Education Press].

Trahar, S. (2007) Teaching And Learning: The International Higher Education Landscape: Some Theories And Working Practices. Bristol: ESCalate. http://escalate.ac.uk/downloads/3559.pdf [accessed 27 May 2013).

China.org.cn [accessed 20 May 2013].

ec.europa.eu (accessed 18 May 2013]. americanprogress.org (accessed 18 February 2013]. aei.gov.au [accessed 17 February 2013).

moe.gov.cn [accessed 12 June 2013].

dayoo.com/roll/201202/14/10000307_105769544.htm [accessed 12 June 2013]. 